Relations industrielles

Industrial Relations

\title{
L'Eglise et la liberté syndicale
}

\section{Maurice Roy}

Volume 12, numéro 4, octobre 1957

URI : https://id.erudit.org/iderudit/1022520ar

DOI : https://doi.org/10.7202/1022520ar

Aller au sommaire du numéro

\section{Éditeur(s)}

Département des relations industrielles de l'Université Laval

ISSN

0034-379X (imprimé)

1703-8138 (numérique)

Découvrir la revue

Citer ce document

Roy, M. (1957). L'Eglise et la liberté syndicale. Relations industrielles / Industrial Relations, 12(4), 404-405. https://doi.org/10.7202/1022520ar
Résumé de l'article

Texte du sermon prononcé par Mgr Maurice Roy devant les syndiqués catholiques de la région de Québec à l'occasion de la Fête du Travail, le 2 septembre 1957, au cours d'une manifestation religieuse organisée par les Syndicats Catholiques de Québec.
Tous droits réservés @ Département des relations industrielles de l’Université Laval, 1957
Ce document est protégé par la loi sur le droit d'auteur. L’utilisation des services d'Érudit (y compris la reproduction) est assujettie à sa politique d'utilisation que vous pouvez consulter en ligne.

https://apropos.erudit.org/fr/usagers/politique-dutilisation/ 


\section{INFORMATIONS}

Deux textes de S. Exc. Mgr Maurice Roy,
archevêque de Québec et primat de l'Eglise canadienne.

\section{1) L'EGLISE ET LA LIBERTE SYNDICALE}

Texte du sermon prononcé par Mgr Maurice Roy devant les syndiqués catholiques de la région de Québec à l'occasion de la Fête du Travail, le 2 septembre 1957, au cours d'une manifestation religieuse organisée par les Syndicats Catholiques de Québec.

Est-il nécessaire de vous rappeler que vos Evêques ont toujours communiqué à leurs ouailles l'enseignement social des Souverains Pontifes et qu'ils vous ont fidèlement témoigné un profond et courageux attachement?

Bien avant les grands développements de l'industrie dans votre province, à une époque où la classe ouvrière comptait beaucoup moins qu'aujourd'hui en nombre et en puissance, vos Evêques ont exposé à leur peuple la doctrine sociale de Léon XIII et du saint Pape Pie X; malgré l'hostilité de certains employeurs et l'indifférence d'un grand nombre d'ouvriers, ils ont exhorté les travailleurs à protéger leurs droits et à pratiquer chrétiennement leur devoir de solidarité en formant des syndicats catholiques.

Les progrès réalisés depuis ce temps sont considérables: les syndicats ouvriers sont devenus des institutions importantes dans notre vie sociale; ils ont formé des chefs compétents et actifs; la législation sociale s'est développée et dans un grand nombre de cas les relations entre employeurs et employés sont devenues plus faciles et même cordiales.

Toutefois, comme il fallait s'y attendre dans un domaine où tant d'intérêts opposés sont en jeu, il reste encore de grands obstacles même sur la voie des réformes les plus nécessaires. «L'Eglise, disait Pie XII, ne peut pas ignorer ou ne pas voir que l'ouvrier, dans son effort pour améliorer sa situation, se heurte à tout un système qui, loin d'être conforme à la nature, est en opposition avec l'ordre de Dieu et avec la fin assignée par Dieu aux biens terrestres ». (Discours et Radiomessages, col. IV, p. 336). Dans un monde économique livré à la libre concurrence et à toutes les passions humaines on voit d'âpres conflits surgir tantôt entre les patrons, tantôt entre patrons et ouvriers, tantôt parmi les ouvriers eux-mêmes. Ces différends, qui naissent ordinairement à l'occasion de négociations sur les salaires et conditions du travail, sont toujours pénibles, mais ils deviennent particulièrement douloureux quand la vie même du syndicat est compromise et que le droit d'association est mis en jeu.

Nous avons vu malheureusement, ici même et ailleurs, ce droit fondamental combattu par certains employeurs. Il y a lieu d'apppliquer à ceux-là la sévère remarque de Pie XI: «On ne voulait pas comp̣rendre que la charité chrétienne exige la reconnaissance de certains droits qui appartiennent à l'ouvrier et que l'Eglise lui a explicitement reconnus». (Au congrès international des patrons chrétiens $1949)$.

Sur ce point précis, vos Evêques n'ont pas manqué de faire écho à l'enseignement des Papes. Dans leur lettre collective sur le problème ouvrier ils ont proclamé bien haut le droit d'association et ils ont formulé les conditions à son exercice normal. Ce document a gardé toute sa valeur et toute son actualité; permettezmoi de vous en rappeler quelques passages. Tout d'abord, à l'adresse des ouvriers: (No 99) «Pour remplir le rôle qui leur revient dans l'économie nationale, pour 
promouvoir leurs intérêts professionnels, pour faire valoir leurs légitimes revendications économiques et sociales, les travailleurs doivent s'unir dans de solides organisations professionnelles. L'Eglise a. depuis Léon XIII, d'immortelle mémoire, proclamé le droit des ouvriers « de s'unir en association afin de pourvoir à leurs intérêts ». Les circonstances présentes rendent encore plus pressante et plus impérieuse l'obligation pour les ouvriers, comme pour les patrons d'ailleurs d'exercer ce droit.

Puis en parlant aux patrons: «Sans doute il n'appartient pas aux patrons d'organiser les syndicats ouvriers et encore moins de s'immiscer dans leur vie propre; toutefois comme tous les citoyens désireux de promouvoir un ordre social chrétien. ils ont la responsabilité de contribuer à leur développement et à leur stabilité ». (333)

Enfin, au sujet de l'Etat: «Le droit d'association est un droit fondamental pour les travailleurs. Il est octroyé par la nature même. L'état a le devoir de protéger ce droit et d'en faciliter l'exercice. Aucun pouvoir ne peut le contester à quelque catégorie de travailleurs que ce soit, du moment que rien, dans une association donnée, ne s'oppose au bien commun et à la sécurité de l'Etat. (174)

Ces quelques lignes extraites d'un long document ne touchent que les principaux points du problème très complexe; mais elles suffisent à montrer que les Evêques n'ont pas craint de l'étudier et d'en donner la solution à la fois la plus précise et la plus concrète. S'il y a des erreurs et des injustices à déplorer, ce n'est pas parce que les Evêques n'ont pas parlé; c'est seulement parce qu'on ne les a pas toujours écoutés. Leur enseignement n'a pas changé: aussi leur parole est-elle aussi vivante aujourd'hui qu'elle l'était hier.

M'adressant maintenant aujourd'hui tout spécialement à vous, chers ouvriers, je me permets d'insister sur vos responsabilités. Un ordre social où règneraient la justice et la charité ne peut être réalisé sans votre loyale et généreuse collaboration. Il faut que votre foi soit éclairée par l'enseignement de l'Eglise et qu'elle inspire tous vos actes; que vous mettiez bien dans votre vie et dans votre foyer chrétien que vous voulez faire régner partout; que vous soyez unis entre vous et avec toutes les autres classes de la société. Rappelez-vous encore les paroles de Léon XIII: «Nous n'avons jamais engagé les catholiques à entrer dans des associations destinées à améliorer le sort du peuple, ni à entreprendre des oeuvres analogues, sans les avertir en même temps que ces institutions devaient avoir la religion pour inspiratrice, pour compagne et pour appui... 》

\section{2) LA RESPONSABILITE DES LAIQUES DANS L'ACTION SOCIALE}

Le 22 septembre 1957, S.Exc. Mgr Maurice Roy, archevêque de Québec et primat de l'Eglise canadienne, prononçait le sermon à l'occasion de la messe traditionnelle qui précède le congrès annuel de la CTCC. Il a précisé le rôle des laïques catholiques dans l'action sociale.

Si l'on tient compte du fait que les syndiqués à qui il s'adressait devaient discuter au cours de ce congrès de l'orientation de leur groupement avec des modifications de structure et même une affiliation éventuelle au CTC, les paroles du primat de l'Eglise canadienne prennent une résonance particulière. Les principes rappelés ne sont pas nouveaux. mais ils sont appliqués à un moment important dans l'évolution du mouvement ouvrier catholique de notre pays. Voild pourquoi nous avons cru opportun de publier les principaux passages de cette allocution.

Après avoir précisé la nature de l'Eglise, corps mystique du Christ, communauté vivante dans laquelle chacun des membres a une part active dans son édification et où chacun a sa part d'initiative que rien ne saurait remplacer, S.Exc. Mgr Roy poursuit :

Le rappel de ces vérités nous semble nécessaire pour comprendre que, dans l'Eglise, les membres ont chacun une fonction spéciale en vue du bien de l'ensemble 